REVIEW

\title{
Assessing vitamin D status: Pitfalls for the unwary
}

\author{
Jeffrey K. C. Lai ${ }^{1}$, Robyn M. Lucas ${ }^{1}$, Mark S. Clements ${ }^{1}$, Simone L. Harrison ${ }^{2}$ and Emily Banks ${ }^{1}$ \\ ${ }^{1}$ National Centre for Epidemiology and Population Health, The Australian National University, Canberra, ACT, \\ Australia \\ ${ }^{2}$ North Queensland Centre for Cancer Research, School of Public Health, Tropical Medicine \& Rehabilitation \\ Sciences, James Cook University, Townsville, Australia
}

The use of vitamin D testing has grown rapidly in the recent times as a result of increased interest in the role of vitamin $\mathrm{D}$ in health. Although the generally accepted measure of vitamin D status is circulating $25(\mathrm{OH}) \mathrm{D}$ concentration, there is little consensus on which assay method should be used. Commonly used assays include competitive proteinbinding assay, RIA, enzyme immunoassay, chemiluminescence immunoassays, HPLC, and LC-MS/MS, each with its own advantages and disadvantages. However, there is significant interassay and interlaboratory variability in measurements. Our simulation of the published data showed that using a deficiency cut-point of $50 \mathrm{nmol} / \mathrm{L}, 57 \%$ of samples assessed using a chemiluminescence immunoassay were classified as deficient compared with $41 \%$ of samples assessed using LC-MS/MS; a 20\% misclassification rate. Similar rates of misclassification were seen at $75 \mathrm{nmol} / \mathrm{L}$. This has implications for clinical practice and decision limits for vitamin D supplementation, suggesting that cut-points should be assay specific rather than universal and that greater harmonization between laboratories is required. Newer assays using alternative biological samples to determine the circulating $25(\mathrm{OH}) \mathrm{D}$ have been proposed and advances in the genetics of vitamin $\mathrm{D}$ and the role of vitamin D-binding protein may improve future assay accuracy.

\section{Keywords:}

25(OH)D / 1,25(OH) ${ }_{2} \mathrm{D} /$ Precision / Vitamin D assay / Vitamin D deficiency
Received: September 26, 2009 Revised: January 11, 2010 Accepted: February 2, 2010

\section{Introduction}

Vitamin D is a 27-carbon secosteroid with a central role in calcium and phosphate homeostasis. The direct pathology of vitamin $\mathrm{D}$ deficiency is osteomalacia in adults and rickets in children. The vitamin D receptor (VDR) is also present in many body tissues $[1,2]$ suggesting that vitamin $D$ also has noncalcaemic actions. Recently, low vitamin D status has been proposed as a risk factor for onset or mortality from a wide

Correspondence: Jeffrey K. C. Lai, National Centre for Epidemiology and Population Health, The Australian National University, Canberra, ACT, 0200, Australia

E-mail: jeffrey.lai@anu.edu.au

Fax: $+61-2-6125-0740$

Abbreviations: ALTM, all laboratory trimmed means; CPBA, competitive protein-binding assay; DBP, vitamin D-binding protein; DEQAS, International Vitamin D External Quality Assessment Scheme; EIA, enzyme immunoassay; FGF, fibroblast growth factor; PTH, parathyroid hormone; UV, ultraviolet; VDR, vitamin $\mathrm{D}$ receptor range of conditions, including various cancers [3-7], type 1 [8] and 2 diabetes $[9,10]$, hypertension [11], multiple sclerosis [12-14], melanoma [15], and some infections [16, 17].

Low vitamin D levels appear to be widespread [18] particularly amongst the elderly [19], populations at high latitudes, dark-skinned and veiled persons, and pregnant women [20]. Evidence also suggests a recent decline in vitamin D status within the population [21]. This has led to guidelines recommending supplementation for at-risk populations $[22,23]$. However the assessment of vitamin D status is controversial, with uncertainties over which metabolites are the most clinically relevant and what levels constitute deficiency. The performance of different assays has led to concerns over reliability of measurements and the validity of interlaboratory comparisons.

\section{Vitamin D physiology}

The major source of vitamin D for healthy adults is from casual exposure to sunlight with a smaller component 
coming from dietary intake. Solar ultraviolet (UV)-B irradiation (280-315 nm) photolyses 7-dehydrocholesterol in the skin to previtamin $\mathrm{D}_{3}$ that is slowly isomerized to vitamin $\mathrm{D}_{3}$ (cholecalciferol). This is taken up into the circulation, bound to vitamin D-binding protein (DBP). Dietary sources include fatty fish (salmon, mackerel), fortified milk, and egg yolks. Plant materials also contribute to vitamin D intake, but this is in the form of vitamin $D_{2}$ (ergocalciferol). Structurally, vitamin $\mathrm{D}_{3}$ and $\mathrm{D}_{2}$ differ in their side chains. Although their metabolic pathways are identical and both contribute to vitamin $\mathrm{D}$ adequacy, vitamin $\mathrm{D}_{3}$ may be more efficiently metabolized to $25(\mathrm{OH}) \mathrm{D}$ than vitamin $\mathrm{D}_{2}$ [24].

Vitamin D (either ergocalciferol or cholecalciferol) is hydroxylated in the liver to calcidiol $(25(\mathrm{OH}) \mathrm{D})$, the major circulating metabolite [1]. In the kidney, $1 \alpha$-hydroxylase enzyme catalyzes a further hydroxylation with the formation of the active hormone, $1,25(\mathrm{OH})_{2} \mathrm{D}$ (calcitriol). Levels of the latter are tightly regulated through a negative feedback control involving upregulation by parathyroid hormone (PTH) and downregulation by higher serum calcium and phosphate levels, as well as via breakdown of the active hormone by a 24 hydroxylase enzyme [25]. Fibroblast growth factor (FGF)-23 inhibits $1 \alpha$-hydroxylase and induces the expression of 24-hydroxylase, thereby suppressing serum $1,25(\mathrm{OH})_{2} \mathrm{D}$ levels. FGF-23 plays a central role in phosphate metabolism [26]. Mutations in FGF-23 and its essential cofactor Klotho protein have been associated with reduced vitamin D activity in mouse models [27].

The best-recognized role of $1,25(\mathrm{OH})_{2} \mathrm{D}$ is in maintaining bone health through the facilitation of intestinal calcium and phosphorus absorption. Noncalcaemic roles are less well understood but may include stimulation of cell differentiation, modulation of activated $\mathrm{T}$ - and B-lymphocyte function [28], production of collagen type 1 , and influence over insulin secretion [29] and muscle function [30].

\section{What to measure and what does it mean?}

The accepted measure of vitamin D status is circulating 25(OH)D concentration [31-33] making quantification of vitamin D status quite unusual, as one of the few clinical situations where a metabolite one step removed from the active factor is used to assess adequacy. However, $25(\mathrm{OH}) \mathrm{D}$ is the most abundant vitamin D metabolite (present in nanomolar concentrations) and is relatively stable (half-life of $\sim 2-3$ wk $[1,34,35])$ making it a good indicator of vitamin D stores. On the contrary, $1,25(\mathrm{OH})_{2} \mathrm{D}$ is present in picomolar concentrations and, because it is tightly regulated, the concentration can remain normal or even elevated, despite evidence of deficiency [1]. Although both 25(OH)D and $1,25(\mathrm{OH})_{2} \mathrm{D}$ are predominantly protein bound in circulation, the total serum level of $25(\mathrm{OH}) \mathrm{D}$ (free and bound and including both $25(\mathrm{OH}) \mathrm{D}_{3}$ and $\left.25(\mathrm{OH}) \mathrm{D}_{2}\right)$ is considered the most appropriate measure of vitamin $\mathrm{D}$ status.
Other markers have been proposed as measures of vitamin D adequacy, e.g. PTH levels or functional outcomes such as bone mineral density or intestinal calcium absorption, but a recent review confirmed that the circulating $25(\mathrm{OH}) \mathrm{D}$ remained the most robust and reliable measure of vitamin D status [36].

Thresholds of serum 25(OH)D concentration to define vitamin D sufficiency are highly debated, with most commentators choosing to adopt biochemically based (i.e. suppression of PTH levels and maintenance of bone mineral density) [37], rather than population-based (i.e. average population levels and distribution), cut-points. Proposals have ranged from $25(\mathrm{OH}) \mathrm{D}$ concentrations of $50 \mathrm{nmol} / \mathrm{L}$ up to concentrations of $82.5 \mathrm{nmol} / \mathrm{L}[30,38-40]$. Most commentators now agree that vitamin D sufficiency should be defined as $25(\mathrm{OH}) \mathrm{D}>75 \mathrm{nmol} / \mathrm{L}$, insufficiency as $50-75 \mathrm{nmol} / \mathrm{L}$, and deficiency as $<50 \mathrm{nmol} / \mathrm{L}$ [41] (Table 1). Many reference laboratories use a normative range of $50-250 \mathrm{nmol} / \mathrm{L}$ [41]. Although the level below which vitamin D supplementation is recommended varies, most laboratories use a threshold of between 30 and $50 \mathrm{nmol} / \mathrm{L}$ [42]. Significant heterogeneity appears to exist between population groups, with lower circulating $25(\mathrm{OH}) \mathrm{D}$ not universally correlating with clinical signs of poor vitamin D status [43, 44].

\section{25(OH)D Assays}

Several assays for 25(OH)D measurement are in common use. The growth in demand for clinical testing [45] has led to commercial kits designed for use in nonspecialist laboratories. Manual and automated immunoassays are the mainstay for most laboratories but LC-MS/MS assays are becoming increasingly common [41].

\subsection{Competitive protein-binding assays}

The first generation competitive protein-binding assay (CPBA) was developed in the early 1970s using various

Table 1. Recently recommended definitions of vitamin D status ${ }^{\text {a) }}$

\begin{tabular}{lll}
\hline Vitamin D status & $\begin{array}{c}25(\mathrm{OH}) \mathrm{D} \\
(\mathrm{nmol} / \mathrm{L})\end{array}$ & Consequences \\
\hline $\begin{array}{l}\text { Vitamin D } \\
\text { sufficiency }\end{array}$ & $>75$ & $\begin{array}{c}\text { Improved efficiency of } \\
\text { intestinal calcium } \\
\text { absorption; nadir } \\
\text { plateau of PTH secretion }\end{array}$ \\
$\begin{array}{c}\text { Vitamin D } \\
\text { insufficiency }\end{array}$ & $50-75$ & $\begin{array}{c}\text { Increased PTH } \\
\text { secretion }\end{array}$ \\
$\begin{array}{c}\text { Vitamin D } \\
\text { deficiency }\end{array}$ & $<50$ & $\begin{array}{c}\text { Reduced bone density } \\
\text { Markedly increased PTH } \\
\text { secretion }\end{array}$ \\
\hline
\end{tabular}

a) Adapted from [41]. 
animal sources of DBP as the primary binding agent, attaching to ${ }^{3} \mathrm{H}-25(\mathrm{OH}) \mathrm{D}[46,47]$. These methods performed quite satisfactorily even when compared with modern assays but were hampered by cumbersome sample extraction and purification. Subsequent techniques attempted to streamline the preparatory process but were limited by matrix interferences from endogenous vitamin $D$ metabolites and gave overestimated results [48, 49]. The CPBA has been superseded by newer technologies and is not commonly used.

\subsection{RIA}

The CPBA requirement for extraction and chromatographic purification was resolved by the development of the first RIA in 1985 [50]. This facilitated a more rapid assay, capable of high-volume throughput. Early RIA used a ${ }^{3} \mathrm{H}-25(\mathrm{OH}) \mathrm{D}$ tracer, but these were subsequently replaced with a more sensitive and rapid radioiodinated $\left({ }^{125} \mathrm{I}\right.$ labeled) tracer [51]. Using this method DiaSorin (Stillwater, $\mathrm{MN}$ ) released the first test kit approved by the US Food and Drug Administration for clinical diagnosis, in 1996. This test uses a polyclonal antibody that has affinity for hydroxylated vitamin D metabolites. Cross-reaction with other nonactive metabolites is possible but these circulate at low levels in comparison with $25(\mathrm{OH}) \mathrm{D}$. Studies have shown that DiaSorin RIA has good recovery of both $25(\mathrm{OH}) \mathrm{D}_{2}$ and $25(\mathrm{OH}) \mathrm{D}_{3}$ [52].

The RIA kit produced by Immunodiagnostic Systems Limited (IDS, Fountain Hills, AZ) uses a ${ }^{125} \mathrm{I}-25(\mathrm{OH}) \mathrm{D}$ tracer coupled with a sheep derived anti-25(OH)D polyclonal antibody that has limited reactivity to $25(\mathrm{OH}) \mathrm{D}_{2}$ (reported around $75 \%$ ). The test may thus underestimate the total $25(\mathrm{OH}) \mathrm{D}$ in situations where the dominant constituent is the $\mathrm{D}_{2}$ metabolite [52-54]. RIA kits for 25(OH)D measurement have been widely used in clinical laboratories [42] but are gradually being replaced by automated methods to cope with increasing demand for $25(\mathrm{OH}) \mathrm{D}$ testing [45].

\subsection{Enzyme immunoassay}

IDS markets an enzyme immunoassay (EIA) where $25(\mathrm{OH}) \mathrm{D}$ is labeled with biotin, added to serum and incubated with the same sheep antibody as the one used in the RIA kit. Chromogenicity is achieved using peroxidaselabeled avidin and tetramethylbenzidine. The IDS EIA kit appears to have less difficulty in binding $25(\mathrm{OH}) \mathrm{D}_{2}$ compared with the RIA kit [54], so that the under-recovery of $25(\mathrm{OH}) \mathrm{D}_{2}$ is lessened [52].

\subsection{Automated instrumentation}

The ${ }^{125}$ I RIA methods commonly in use have limited automation capacity. In contrast, the EIA uses a nonra- dioactive enzyme that allows automation when used together with an ELISA processor. However, comparisons of different ELISA processors with DiaSorin RIA revealed large variations between different methods [55]. Recent advances, such as competitive chemiluminescence technology, have allowed a shift from the labor-intensive, manual assays to faster, safer automated systems more suited to the needs of clinical laboratories.

Possibly the main commercial product available is the DiaSorin LIAISON ${ }^{\circledR}$ analyzer that uses an antibody against 25(OH)D. The LIAISON ${ }^{\circledR}$ system appears to compare favorably with DiaSorin RIA, with correlations ranging from $r=0.71$ [55] to $r=0.88$ [56] although evidence suggests that the reproducibility of $25(\mathrm{OH}) \mathrm{D}$ levels of this assay may be suboptimal [45] and assay-specific decision limits may need to be adopted [57]. The (now defunct [58]) Nichols ADVANTAGE $^{\circledR}$ (San Clemente, CA) used purified human $\mathrm{DBP}$ as the competitive binder, but the validity of this assay has been questioned, with multiple studies suggesting a significant overestimation of $25(\mathrm{OH}) \mathrm{D}_{3}$ and underestimation of $25(\mathrm{OH}) \mathrm{D}_{2}$ [59-61]. The more recent Roche ELECSYS $^{\circledR}$ assay is a direct electrochemiluminescence immunoassay and is specific for $25(\mathrm{OH}) \mathrm{D}_{3}$. Initial results demonstrate a good overall agreement with DiaSorin RIA $(r=0.836)$, HPLC $(r=0.808)$ and LC-MS/MS $(r=0.8157)$, although concerns have been raised over spuriously high results near optimal $25(\mathrm{OH}) \mathrm{D}$ cut-off points (e.g. $50-80 \mathrm{nmol} / \mathrm{L})$ [62].

\subsection{HPLC}

UV quantitative detection following HPLC was first developed in 1977 and was a significant advancement from the CPBA methods used at the time [63]. A significant advantage of HPLC is its ability to separately assay $25(\mathrm{OH}) \mathrm{D}_{3}$ and $25(\mathrm{OH}) \mathrm{D}_{2}$. Although the total serum $25(\mathrm{OH}) \mathrm{D}$ is thought to be the best measure of vitamin D status [58], separate quantification may be of interest to discern the contribution of exogenous sources where this is in the form of vitamin $\mathrm{D}_{2}$, as is typical for vitamin $\mathrm{D}$ supplements in the United States, Japan, and parts of Europe [53]. HPLC is considered a reliable and robust method of determining vitamin $\mathrm{D}$ concentrations, but is not well suited to many clinical laboratories, as it requires expensive equipment, specific technical expertise, large sample volumes, and has limited sample throughput.

Several commercial kits are available for analytical HPLC separation including products from Immundiagnostik AG (Bensheim, Germany) and ESA Biosciences (Chelmsford, MA). The Immunodiagnostik kit requires samples to be precipitated and solid phase extracted using $\mathrm{C}_{18}$ cartridges to remove high molecular weight substances before injection into the HPLC system. Quantitation is via UV detection at $264 \mathrm{~nm}$. The ESA Biosciences kit includes an internal standard and uses an ESA electrochemical detector 
(Coulochem ${ }^{\circledR}$ III or CoulArray ${ }^{\circledR}$ ) equipped with a dual coulometric electrochemical cell. This system requires smaller sample volumes than the absorbance detectors. Detailed data on the performance of these kits are not reported in the literature.

\subsection{LC-MS/MS}

LC-MS/MS can potentially offer improved sensitivity and specificity compared with immunoassays and competitive binding assays [64]. Like HPLC, LC-MS/MS is also able to separately quantify $25(\mathrm{OH}) \mathrm{D}_{3}$ and $25(\mathrm{OH}) \mathrm{D}_{2}$ and is free of interference from dihydroxy metabolites of vitamin $\mathrm{D}$. When performed by well-trained operators, LC-MS/MS is very accurate with results strongly correlated with those from commercial DiaSorin RIA ( $r=0.91$ [64]) and HPLC $(r=0.99$ [65]). Limitations include expensive equipment, lower capacity for throughput compared with automated platforms, ion suppression $[65,66]$, and interference from inactive isomers [67].

Despite being considered by many commentators as the gold standard assay [66], significant interlaboratory variations in LC-MS/MS measurements has been reported. A major factor cited is poor assay standardization, leading to calls for the use of a common standard that can at least partially resolve interlaboratory variations [68]. Recently, Quest Diagnostics, the largest medical laboratory in the United States, acknowledged erroneous $25(\mathrm{OH}) \mathrm{D}$ results reported to doctors using their LC-MS/MS assay. In the New York Times article, a spokesman for Quest cited faulty calibration and poor adherence to procedures in some laboratories as reasons for the generally elevated results [69]. According to a communication from Quest, these issues have now been resolved and internal data using standard reference materials show performance in line with the gold standard (LC-MS/MS methodology performed by the National Institute of Standards and Technology)(personal communication, W. A. Salameh). The adoption of LC-MS/MS methods is likely to grow in the near future, but better controls and greater standardization are necessary before widespread acceptance of this assay.

\subsection{GC-MS}

GC-MS is similar to LC-MS/MS except that the mobile stage of chromatography utilizes an inert gas rather than a liquid solvent. Unlike LC-MS/MS that is easier to use, GC-MS is not commonly used in the clinical analysis of $25(\mathrm{OH}) \mathrm{D}$ although methods have been described in the literature [70, 71].

\section{$5 \quad 1,25(\mathrm{OH})_{2} \mathrm{D}$ Assays}

Measuring serum $1,25(\mathrm{OH})_{2} \mathrm{D}$ is more difficult than its precursor $25(\mathrm{OH}) \mathrm{D}$ as it is highly lipophilic, rapidly unstable, and circulates at picomolar concentrations $(\mathrm{pmol} / \mathrm{L})$ that are below the detection limits of direct UV or MS methods. The determination of $1,25(\mathrm{OH})_{2} \mathrm{D}$ is also complicated by the crossreactivity of antibodies to other vitamin $\mathrm{D}$ metabolites, thus requiring sample prepurification often involving extensive chromatographic techniques [72]. This has proven to be cumbersome and although advances have been made the development of an acceptable, rapid assay has proven to be challenging [67]. As previously noted, $1,25(\mathrm{OH})_{2} \mathrm{D}$ concentration can be maintained even when $25(\mathrm{OH}) \mathrm{D}$ levels are low. As such, $1,25(\mathrm{OH})_{2} \mathrm{D}$ has limited clinical relevance in understanding vitamin D status and is not routinely tested.

Radioreceptor assays and immunoassays, both RIA and EIA, have been developed for quantifying $1,25(\mathrm{OH})_{2} \mathrm{D}$. The first Radioreceptor assay, using a chicken intestinal VDR, was introduced in 1974 [73]. The need to isolate VDR as a binding agent was removed with the introduction of the first RIA in 1978 [74]. As for 25(OH)D assays, the currently available RIA, such as the DiaSorin and IDS RIA, use ${ }^{125} \mathrm{I}$ based tracers. IDS also markets an EIA kit that employs a calorimetric detection system and can be automated when coupled with an ELISA processor. It is likely that automated platforms will become more common in the near future with DiaSorin soon planning to market a $1,25(\mathrm{OH})_{2} \mathrm{D}$ platform based on its LIAISON ${ }^{\circledR}$ system (http://www.diasorin.com/en/productsandsystems/bone).

\section{Variation in 25(OH)D measurement}

The use of vitamin D testing has grown exponentially in recent times as the result of increased interest in the role of vitamin D in health. Despite this there is little consensus on which assay method should be used to measure 25(OH)D and the ongoing concerns about the reliability of measurements [45, 61, 75]. This raises two distinct questions; first whether the assay can measure the "true" 25(OH)D level, and second whether these results are repeatable within and between laboratories. Thus, the first issue is one of the accuracy and the second of precision.

The International Vitamin D External Quality Assessment Scheme (DEQAS) was set up in 1989 to address the poor performance of the $25(\mathrm{OH}) \mathrm{D}$ and $1,25(\mathrm{OH})_{2} \mathrm{D}$ assays. DEQAS distributes serum samples to participating laboratories worldwide on a quarterly basis and collates returned results, establishing all laboratory trimmed means (ALTMs), method means, and SDs [42, 59]. Performance targets are established and certificates of proficiency awarded to complying laboratories. In October 2009, the results were collected from 612 participating laboratories [76].

\subsection{Intra-assay, between laboratory variability}

DEQAS data from the October 2009 Distribution [76], comparing pooled means across several laboratories using 
the same assay method, revealed that DiaSorin LIAISON ${ }^{\circledR}$ Total, DiaSorin RIA, IDS EIA, automated IDS EIA, IDS RIA, HPLC and LC-MS/MS all had similar results with mean biases across the five samples within $9 \%$ of the ALTM. The exception was the Roche ELECSYS ${ }^{\mathbb{R}}$ that recorded an average positive bias of $20 \%$ compared with the ALTM. This was particularly evident at lower $25(\mathrm{OH}) \mathrm{D}$ levels.

Considering the variation between laboratories reveals that each one of the above assays had an interlaboratory coefficient of variation of at least $14 \%$ for at least one sample. This suggests that on an average, 1 in 20 laboratories will give a mean measurement of greater than $28 \%$ difference to the method mean for that assay. HPLC and Roche ELECSYS ${ }^{\circledR}$ had coefficients of variation in excess of $25 \%$ suggesting that one in twenty laboratories will give results less than one-half or greater than one and a half times the method mean.

The increased use of more advanced HLPC and LC-MS/ MS may potentially improve accuracy and give means in close concordance, but there remains significant interlaboratory variability [75].

\subsection{Interassay variability}

Significant interassay variation in the mean measurements has been commonly reported [55, 61, 77]. Although the ALTM has been suggested as a suitable proxy for the GCMS-derived values [71], the use of the percentage deviation from the ALTM as a measure of method accuracy is potentially biased [52]. As the composite average of method means, the ALTM will be influenced toward the dominant assay in use and systemic biases may be masked or minimized. Furthermore, in an experiment where exogenous $25(\mathrm{OH}) \mathrm{D}_{3}$ and $25(\mathrm{OH}) \mathrm{D}_{2}$ were added to the serum to give known final concentrations, and then the samples sent to laboratories for routine $25(\mathrm{OH}) \mathrm{D}$ assay, the percentage "recovery" of the exogenous $25(\mathrm{OH}) \mathrm{D}$ varied substantially between assay methods (Table 2) [52].

The accuracy of various assays may be affected by several factors. Most manufacturers claim a $100 \%$ cross-reactivity between $25(\mathrm{OH}) \mathrm{D}_{3}$ and $25(\mathrm{OH}) \mathrm{D}_{2}$. However, Nichols
ADVANTAGE ${ }^{\circledR}$ and the DiaSorin and IDS RIA have all been reported to yield lower measurements of $25(\mathrm{OH}) \mathrm{D}_{2}$ compared with other assays [52, 59, 61, 65], while the DiaSorin RIA, IDS RIA and Nichols ADVANTAGE CPBA have been reported to yield higher measurements of 25(OH) $D_{3}$ [61] compared with HPLC. However, without the use of a common standard, it is not certain which assays are underestimating, and which assays are overestimating, the true values. Cross-reactivity to other vitamin D metabolites, including $1,25(\mathrm{OH})_{2} \mathrm{D}$, may also exist although the small concentrations of the active metabolite are unlikely to significantly affect the overall concentrations. LC-MS/MS has been noted to cross-react with the inactive 3-epi$25(\mathrm{OH}) \mathrm{D}_{3}$ isomer present in newborn infants and children $[65,67]$, where the contribution to total $25(\mathrm{OH}) \mathrm{D}$ may be as high as $8.7-61.1 \%$ [78].

\subsection{Implications of measurement variability}

Many clinical decisions are based on clear reference limits. The currently proposed vitamin D sufficiency cut-points (Table 1) were developed based on a specific assay used in the relevant experiment, with most using the DiaSorin RIA kit. Variability across assays, even if there was good interlaboratory agreement for a particular assay, calls into question the relevance of defining a cut-point without defining the assay from which it was derived. Without harmonization between assays, reference limits are of limited clinical utility. Nevertheless, poor accuracy alone can be overcome by establishing assay-specific reference ranges $[61,79,80]$. However, this does not overcome the problems associated with lack of precision of a particular assay within and between laboratories. For many assays, particularly nonautomated types, accuracy and precision are largely user dependent [42, 45].

Recently, the National Institute of Standards and Technology, in conjunction with the National Institutes of Health's Office of Dietary Supplements, has developed a standard reference material to aid in vitamin D analysis. Standard reference material 972 vitamin D in human serum consists of four pools of human serum with analyte values for $25(\mathrm{OH}) \mathrm{D}_{2}, 25(\mathrm{OH}) \mathrm{D}_{3}$, and 3-epi-25(OH) $\mathrm{D}_{3}[81]$. This can

Table 2. Comparison of assay methods using DEQAS data ${ }^{\text {a) }}$

\begin{tabular}{llccc}
\hline Assay method & $\begin{array}{l}\text { Number of } \\
\text { laboratories }\end{array}$ & $\begin{array}{l}\text { Variation from weighted mean for } \\
\text { endogenous 25(OH)D (\%) }\end{array}$ & $\begin{array}{l}\text { Recovery of exogenous } \\
25\left(\mathrm{OH}_{1} \mathrm{D}_{3}(\%)\right.\end{array}$ & $\begin{array}{l}\text { Recovery of exogenous } \\
25(\mathrm{OH}) \mathrm{D}_{2}(\%)\end{array}$ \\
\hline DiaSorin RIA & 53 & -8.5 & 82.1 & 83.2 \\
DiaSorin LIAISON & 16 & -14.1 & 81.4 & 88.6 \\
IDS OCTEIA & 16 & -15.1 & 54.2 & 29.1 \\
IDS RIA & 21 & 10.4 & 78.8 & 56.4 \\
Nichols ADVANTAGE & 21 & 37.5 & 46.4 & 43.2 \\
HPLC & 6 & -0.6 & 112.2 & 97.1 \\
LC-MS/MS & 4 & -20.7 & 111.5 & 118.1 \\
\hline
\end{tabular}

a) Adapted from [52]. 
serve as a reproducible standard of comparison and a useful addition to quality assurance programs such as DEQAS.

The performance target set by DEQAS in 2000 requires participating laboratories to have at least $80 \%$ of measurements within $\pm 30 \%$ of the ALTM. In 2003 , only $59 \%$ of the participants satisfied this very generous target [42]. This provides little confidence to clinicians who are required to make treatment decisions based on laboratory results. Unsurprisingly, there is still much confusion on the interpretation of $25(\mathrm{OH}) \mathrm{D}$ results. More focus needs to be placed on the reproducibility of measurements [45] and not just the overall assay means, which have little relevance in clinical settings. Harmonization of assays or the establishment of method-/laboratory-specific decision limits may assist in removing the reliance upon universal reference limits [79].

\section{An example}

To illustrate the implications of assay variation for clinicians and laboratories, we reinterpret results from the comparison by Roth et al. [82] using LC-MS/MS and DiaSorin LIAISON 1 and 2. The LIAISON $25(\mathrm{OH}) \mathrm{D}$ assay (LIAISON 1) was superseded by the modified $25(\mathrm{OH})$ D TOTAL assay (LIAISON 2) in 2007, but both the assays are included to assist in the interpretation of previously published studies. Using estimates from Roth et al. [82], we assumed that (i) the mean 25(OH)D for LC-MS/MS was $68 \mathrm{nmol} / \mathrm{L}$, the mean 25(OH)D for LIAISON 1 was $68 \times 0.79=53.7 \mathrm{nmol} / \mathrm{L}$, and the mean for LIAISON 2 was $68 \times 0.92=62.6 \mathrm{nmol} / \mathrm{L}$, and (ii) the SD for LC-MS $/$ MS was $43.5 \mathrm{nmol} / \mathrm{L}$; we further assumed that (iii) the coefficient of variation (SD/mean) was the same for both LC-MS/MS and LIAISON 1 and 2, (iv) the logs of the measurement values were normally distributed and, (v) the correlation between LC-MS/ MS and LIAISON 1 is $r=0.90$ and LC-MS/MS and LIAISON 2 is $r=0.95$. Here we have classified vitamin D status according to reference limits commonly used in clinical practice.

The mean[SD] 25(OH)D level measured using LC-MS/MS was $68.0[43.5] \mathrm{nmol} / \mathrm{L}$ with $40.8 \%$ classified as deficient with a cut-point of $<50 \mathrm{nmol} / \mathrm{L}$ and $67.7 \%$ classified as deficient with a cut-point of $<75 \mathrm{nmol} / \mathrm{L}$. Using the DiaSorin LIAISON 1, the mean[SD] $25(\mathrm{OH}) \mathrm{D}$ for the same samples was

Table 3. Percentage of subjects classified as above and below 50 and $75 \mathrm{nmol} / \mathrm{L}$ using LC-MS/MS and DiaSorin LIAISON $1^{\text {a) }}$

\begin{tabular}{lllll}
\hline LCMS/MS & \multicolumn{4}{c}{ DiaSorin LIAISON 1 } \\
\cline { 2 - 5 } & $\begin{array}{l}<50 \\
\mathrm{nmol} / \mathrm{L}\end{array}$ & $\begin{array}{l}\geq 50 \\
\mathrm{nmol} / \mathrm{L}\end{array}$ & $\begin{array}{l}<75 \\
\mathrm{nmol} / \mathrm{L}\end{array}$ & $\begin{array}{l}\geq 75 \\
\mathrm{nmol} / \mathrm{L}\end{array}$ \\
\hline$<50 \mathrm{nmol} / \mathrm{L}$ & 39.0 & 1.8 & & \\
$\geq 50 \mathrm{nmol} / \mathrm{L}$ & 17.8 & 41.4 & & \\
$<75 \mathrm{nmol} / \mathrm{L}$ & & & 66.3 & 1.4 \\
$\geq 75 \mathrm{nmol} / \mathrm{L}$ & & & 14.3 & 18.0 \\
\hline
\end{tabular}

a) Data adapted from [82].
$53.7[34.4] \mathrm{nmol} / \mathrm{L}$, with $56.8 \%$ classified as deficient at $<50 \mathrm{nmol} / \mathrm{L}$ and $80.6 \%$ at $<75 \mathrm{nmol} / \mathrm{L}$ (Table 3). Using the DiaSorin LIAISON 2, the mean[SD] 25(OH)D for the same samples was 62.6[40.0] nmol/L, with $46.5 \%$ classified as deficient at $<50 \mathrm{nmol} / \mathrm{L}$ and $72.7 \%$ at $<75 \mathrm{nmol} / \mathrm{L}$ (Table 4$)$. Hence, at threshold levels of 50 and $75 \mathrm{nmol} / \mathrm{L}, 18 \%$ (8\%) and $14 \%(7 \%)$ of the subjects respectively were classified as vitamin D sufficient using LC-MS/MS but deficient using DiaSorin LIAISON 1 (LIAISON 2). Conversely, 2\% (3\%) of subjects at $50 \mathrm{nmol} / \mathrm{L}$ and $1 \%(2 \%)$ at $75 \mathrm{nmol} / \mathrm{L}$ were classified as vitamin D sufficient using DiaSorin LIAISON 1 (LIAISON 2) but deficient using LC-MS/MS.

To place these results in context, if subjects with $25(\mathrm{OH}) \mathrm{D}$ levels $<50 \mathrm{nmol} / \mathrm{L}$ were universally supplemented with vitamin $\mathrm{D}$ then almost one in five subjects would not receive supplementation using LC-MS/MS measurements that would have otherwise received supplementation using DiaSorin LIAISON 1 measurements. The degree of misclassification between LC-MS/MS and LIAISON 1 was one in six at $75 \mathrm{nmol} / \mathrm{L}$. The DiaSorin LIAISON 2 assay performed better, with the overall degree of misclassification of around one in ten subjects at both 50 and $75 \mathrm{nmol} / \mathrm{L}$. This shows that the newer 25(OH)D TOTAL assay (LIAISON 2) offers improved performance over the older $25(\mathrm{OH}) \mathrm{D}$ assay (LIAISON 1). However, many studies commonly referenced in the literature report measurements from the superseded assay.

Measurement uncertainty should also be taken into consideration for interpretation of $25(\mathrm{OH}) \mathrm{D}$ results. If "adequacy" above a certain cut-point is desired (e.g. $80 \mathrm{nmol} / \mathrm{L}$ ), then aiming for measurements in excess of this level (e.g. $100 \mathrm{nmol} / \mathrm{L}$ ) may be necessary to ensure that the true level is obtained [83]. This highlights the dangers of adopting universal reference limits between assays and laboratories and the misleading conclusions that can be drawn by clinicians from single $25(\mathrm{OH}) \mathrm{D}$ measurements.

\section{25(OH)D in alternative biological samples}

Although 25(OH)D is usually measured in serum from venous blood, a number of other sample types are now

Table 4. Percentage of subjects classified as above and below 50 and $75 \mathrm{nmol} / \mathrm{L}$ using LC-MS/MS and DiaSorin LIAISON $2^{\text {a) }}$

\begin{tabular}{lcccc}
\hline \multirow{2}{*}{ LCMS/MS } & \multicolumn{4}{c}{ DiaSorin LIAISON 2 } \\
\cline { 2 - 5 } & $\begin{array}{c}<0 \\
\mathrm{nmol} / \mathrm{L}\end{array}$ & $\begin{array}{l}\geq 50 \\
\mathrm{nmol} / \mathrm{L}\end{array}$ & $\begin{array}{l}<75 \\
\mathrm{nmol} / \mathrm{L}\end{array}$ & $\begin{array}{l}\geq 75 \\
\mathrm{nmol} / \mathrm{L}\end{array}$ \\
\hline$<50 \mathrm{nmol} / \mathrm{L}$ & 38.1 & 8.3 & & \\
$\geq 50 \mathrm{nmol} / \mathrm{L}$ & 2.7 & 50.9 & & \\
$<75 \mathrm{nmol} / \mathrm{L}$ & & & 65.4 & 7.3 \\
$\geq 75 \mathrm{nmol} / \mathrm{L}$ & & & 2.3 & 25.0 \\
\hline
\end{tabular}

a) Data adapted from [82]. 
being investigated. There is a high correlation between the 25(OH)D levels from capillary blood and those from venous blood $(r=0.91)$, while the former involves a lower blood volume, and is cheaper and easier to collect. However, there is a significant positive bias [84], possibly attributable to the collection method, skin contamination, interaction with adipose tissue or haemodilution. Thus, capillary and venous blood results cannot be used interchangeably but may require a correction factor or source-specific decision limits to guide the assessment of $25(\mathrm{OH}) \mathrm{D}$ status.

Newer LC-MS/MS assays require as little as $3.28 \mu \mathrm{L}$ of whole blood and perform comparably DiaSorin RIA $(r=0.95)$ that requires a sample of $50 \mu \mathrm{L}$ [85]. Recent reports indicate successful measurement of $25(\mathrm{OH}) \mathrm{D}$ from dried blood spots such as those routinely collected in neonatal screening programs. Such testing would facilitate mass screening of newborn infants where poor vitamin D status is common [20, 85] and provide a rich data source for researchers aiming to understand the possible associations between early life vitamin D status and disease susceptibility in later life [86].

LC-MS/MS has also been adapted to saliva samples, with initial small studies showing salivary $25(\mathrm{OH}) \mathrm{D}_{3}$ to be well correlated with the serum levels $(r=0.83 p<0.01)$ despite lower concentrations attributable to the absence of $25(\mathrm{OH}) \mathrm{D}$ bound to DPB $[87,88]$. Larger studies investigating the validity of saliva samples and the impact of $25(\mathrm{OH}) \mathrm{D}_{2}$ (amongst other issues) are necessary before widespread clinical use. Saliva sampling is potentially useful for assessment of the vitamin D status of groups where venepuncture is difficult, such as children.

\section{The role of genetic variation and vitamin D levels}

Serum 25(OH)D levels are highly dependent on environmental and lifestyle factors, particularly exposure to UV-B radiation. Nevertheless, serum $25(\mathrm{OH}) \mathrm{D}$ variation has a significant hereditable component as demonstrated in the twin studies [89]. Polymorphisms in the CYP27B1 gene that encodes 25-hydoxyvitamin D $1 \alpha$-hydroxylase, are significantly associated with 25(OH)D levels [90]. Mutations in this gene cause rickets [91] and it is proposed as a strong candidate for a causal autoimmune susceptibility gene, with roles in diseases including multiple sclerosis [92] and type 1 diabetes [93].

DBP, also known as Gc or group-specific component, is the major transporter of vitamin $\mathrm{D}$ metabolites in circulation [94]. DBP phenotype is a predictor of $25(\mathrm{OH}) \mathrm{D}$ concentrations with highest levels in Gc1-1 (Gc1s-1s, Gc1s1f, Gc1f-1f), intermediate in Gc1-2 (Gc1s-2, Gc1f-2), and lowest in Gc2-2 [95]. Interestingly, the prevalence of vitamin $\mathrm{D}$ deficiency (as measured by PTH, bone mineral density, $\mathrm{BMC}$, and bone markers) was consistent across phenotypes, suggesting that the thresholds for vitamin D deficiency may be phenotype specific [95]. Certain polymorphisms may be more efficient at binding, activating, and metabolizing [96] vitamin $\mathrm{D}$ and therefore require lower circulating levels. Thus, genetic polymorphisms are a likely contributor to the heterogeneity in clinical manifestations of seemingly low vitamin D status, especially across racial groups [43].

\section{Concluding remarks}

There remain a number of issues in the measurement of vitamin D status that pose significant dilemmas for clinicians, laboratories, and researchers. First, there remains a lack of consensus as to the $25(\mathrm{OH}) \mathrm{D}$ concentration that denotes vitamin D sufficiency or guides when treatment of insufficiency is necessary. Second, significant between-assay and between-laboratory variability persists. Thus, defining vitamin $\mathrm{D}$ deficiency according to a single universal cutpoint is not currently appropriate and any single measure of $25(\mathrm{OH}) \mathrm{D}$ may not be reliable in detecting vitamin $\mathrm{D}$ deficiency.

Clinicians need to recognize the limitations of current assays, and seek guidance from cutoff points calibrated to the specific assay and laboratories being used.

Laboratories must work toward more widespread provision of assay and laboratory-specific decision limits and the harmonization of methods to improve the interpretability of serum 25(OH)D measurements [57, 79, 80]. Interlaboratory variability can be improved with stricter implementation of procedures, calibration, and the use of common standards [68].

Research regarding the health effects of vitamin D generally aims to compare serum $25(\mathrm{OH}) \mathrm{D}$ levels in those with and without the condition of interest. This review underlines the importance of using relative levels of vitamin D (e.g. tertiles, quintiles), rather than absolute cutoff points, and using the same laboratory and assay methods, preferably in batched analysis, for comparisons within the population under study. Caution should be exercised when commenting on health effects relating to absolute $25(\mathrm{OH}) \mathrm{D}$ levels and the likely effect of the chosen assay methods noted.

Consideration of vitamin D status has progressed remarkably since the first assays were developed in the early 1970 s. Critical evaluation of the appropriate analyte, careful study of optimal physiological levels, and the ongoing development of increasingly sophisticated assay methods have accompanied the rapidly growing interest in the diversity of the health effects of vitamin D. For this progress to continue, there is now an urgent need for standardization and calibration of assay methods.

A/Prof Banks is funded by an NHMRC Research Fellowship; Dr. Clements is funded by an NHMRC Career Development Award and Dr. Harrison is supported by the Cancer Council Queensland John McCaffrey Research Fellowship.

The authors have declared no conflict of interest. 


\section{References}

[1] Holick, M. F., Sunlight and vitamin D for bone health and prevention of autoimmune diseases, cancers, and cardiovascular disease. Am. J. Clin. Nutr. 2004, 80, 1678S-1688S.

[2] Walters, M. R., Newly identified actions of the vitamin-D endocrine system. Endocr. Rev. 1992, 13, 719-764.

[3] Garland, C. F., Garland, F. C., Gorham, E. D., Lipkin, M. et al., The role of vitamin D in cancer prevention. Am. J. Public Health 2006, 96, 252-261.

[4] Garland, C. F., Gorham, E. D., Mohr, S. B., Grant, W. B. et al., Vitamin D and prevention of breast cancer: pooled analysis. J. Steroid Biochem. Mol. Biol. 2007, 103, 708-711.

[5] Gorham, E. D., Garland, C. F., Garland, F. C., Grant, W. B. et al., Optimal vitamin D status for colorectal cancer prevention: a quantitative meta analysis. Am. J. Prev. Med. 2007, 32, 210-216.

[6] Holick, M. F., Vitamin D deficiency. N. Engl. J. Med. 2007, 357, 266-281.

[7] Gupta, D., Lammersfeld, C. A., Trukova, K., Lis, C. G., Vitamin $D$ and prostate cancer risk: a review of the epidemiological literature. Prostate Cancer Prostatic Dis. 2009, 12, 215-226.

[8] Hypponen, E., Laara, E., Reunanen, A., Jarvelin, M. R. et al., Intake of vitamin $D$ and risk of type 1 diabetes: a birth-cohort study. Lancet 2001, 358, 1500-1503.

[9] Mathieu, C., Gysemans, C., Giulietti, A., Bouillon, R., Vitamin D and diabetes. Diabetologia 2005, 48, 1247-1257.

[10] Pittas, A. G., Dawson-Hughes, B., Li, T., Van Dam, R. M. et al., Vitamin $\mathrm{D}$ and calcium intake in relation to type 2 diabetes in women. Diabetes Care 2006, 29, 650-656.

[11] Forman, J. P., Curhan, G. C., Taylor, E. N., Plasma 25hydroxyvitamin $\mathrm{D}$ levels and risk of incident hypertension among young women. Hypertension 2008, 52, 828-832.

[12] Munger, K. L., Levin, L. I., Hollis, B. W., Howard, N. S. et al., Serum 25-hydroxyvitamin $D$ levels and risk of multiple sclerosis. J. Am. Med. Assoc. 2006, 296, 2832-2838.

[13] Ascherio, A., Munger, K., Epidemiology of multiple sclerosis: from risk factors to prevention. Semin. Neurol. 2008, 28, 17-28.

[14] Cantorna, M. T., Vitamin D and multiple sclerosis: an update. Nutr. Rev. 2008, 66, S135-S138.

[15] Newton-Bishop, J. A., Beswick, S., Randerson-Moor, J., Chang, Y. M. et al., Serum 25-hydroxyvitamin D3 levels are associated with breslow thickness at presentation and survival from melanoma. J. Clin. Oncol. 2009, 27, 5439-5444.

[16] Bikle, D. D., Vitamin D and the immune system: role in protection against bacterial infection. Curr. Opin. Nephrol. Hypertens. 2008, 17, 348-352.

[17] Cannell, J. J., Zasloff, M., Garland, C. F., Scragg, R. et al., On the epidemiology of influenza. Virol. J. 2008, 5, 29.

[18] Ginde, A. A., Liu, M. C., Camargo, C. A., Jr., Demographic differences and trends of vitamin $D$ insufficiency in the US population, 1988-2004. Arch. Intern. Med. 2009, 169, 626-632.
[19] Kuchuk, N. O., Pluijm, S. M., van Schoor, N. M., Looman, C. W. et al., Relationships of serum 25-hydroxyvitamin D to bone mineral density and serum parathyroid hormone and markers of bone turnover in older persons. J. Clin. Endocrinol. Metab. 2009, 94, 1244-1250.

[20] Munns, C., Zacharin, M. R., Rodda, C. P., Batch, J. A. et al., Prevention and treatment of infant and childhood vitamin $D$ deficiency in Australia and New Zealand: a consensus statement. Med. J. Aust. 2006, 185, 268-272.

[21] Looker, A. C., Pfeiffer, C. M., Lacher, D. A., Schleicher, R. L. et al., Serum 25-hydroxyvitamin D status of the US population: 1988-1994 compared with 2000-2004. Am. J. Clin. Nutr. 2008, 88, 1519-1527.

[22] Working Group of the Australian and New Zealand Bone and Mineral Society. Endocrine society of Australia and osteoporosis Australia, vitamin D and adult bone health in Australia and New Zealand: a position statement. Med. J. Aust. 2005, 182, 281-285.

[23] Qaseem, A., Snow, V., Shekelle, P., Hopkins, R., Jr. et al., Pharmacologic treatment of low bone density or osteoporosis to prevent fractures: a clinical practice guideline from the American College of Physicians. Ann. Intern. Med. 2008, 149, 404-415.

[24] Trang, H. M., Cole, D. E. C., Rubin, L. A., Pierratos, A. et al., Evidence that vitamin D-3 increases serum 25-hydroxyvitamin D more efficiently than does vitamin D-2. Am. J. Clin. Nutr. 1998, 68, 854-858.

[25] Brown, E. M., Pollak, M., Seidman, C. E., Seidman, J. G. et al., Seminars in medicine of the Beth-Israel-Hospital, Boston - calcium-ion-sensing cell-surface receptors. N. Engl. J. Med. 1995, 333, 234-240.

[26] Kiela, P. R., Ghishan, F. K., Recent advances in the renalskeletal-gut axis that controls phosphate homeostasis. Lab. Invest. 2009, 89, 7-14.

[27] Razzaque, M. S., Sitara, D., Taguchi, T., St-Arnaud, R. et al., Premature aging-like phenotype in fibroblast growth factor 23 null mice is a vitamin D-mediated process. FASEB J. 2006, 20, 720-722.

[28] Bhalla, A. K., Amento, E. P., Clemens, T. L., Holick, M. F., et al., Specific high-affinity receptors for 1,25-dihydroxyvitamin-D3 in human peripheral-blood mononuclear-cells presence in monocytes and induction in lymphocytes-T following activation. J. Clin. Endocrinol. Metab. 1983, 57, 1308-1310.

[29] Lee, S., Clark, S. A., Gill, R. K., Christakos, S., 1,25-Dihydroxyvitamin-D(3) and pancreatic beta-cell function - vitamin-D receptors, gene-expression, and insulin-secretion. Endocrinology 1994, 134, 1602-1610.

[30] Bischoff-Ferrari, H. A., Giovannucci, E., Willett, W. C., Dietrich, T. et al., Estimation of optimal serum concentrations of 25-hydroxyvitamin $D$ for multiple health outcomes. Am. J. Clin. Nutr. 2006, 84, 18-28.

[31] Holick, M. F., Vitamin D: a millenium perspective. J. Cell. Biochem. 2003, 88, 296-307.

[32] Holick, M. F., Vitamin D: importance in the prevention of cancers, type 1 diabetes, heart disease, and osteoporosis. Am. J. Clin. Nutr. 2004, 79, 362-371. 
[33] Hart, G. R., Furniss, J. L., Laurie, D., Durham, S. K., Measurement of vitamin D status: background, clinical use, and methodologies. Clin. Lab. 2006, 52, 335-343.

[34] Barragry, J. M., France, M. W., Corless, D., Gupta, S. P. et al., Intestinal cholecalciferol absorption in the elderly and in younger adults. Clin. Sci. Mol. Med. 1978, 55, 213-220.

[35] Clemens, T. L., Zhou, X. Y., Myles, M., Endres, D. et al., Serum vitamin D2 and vitamin D3 metabolite concentrations and absorption of vitamin D2 in elderly subjects. J. Clin. Endocrinol. Metab. 1986, 63, 656-660.

[36] Seamans, K. M., Cashman, K. D., Existing and potentially novel functional markers of vitamin D status: a systematic review. Am. J. Clin. Nutr. 2009, 89, 1997S-2008S.

[37] Chapuy, M. C., Preziosi, P., Maamer, M., Arnaud, S. et al., Prevalence of vitamin $D$ insufficiency in an adult normal population. Osteoporos. Int. 1997, 7, 439-443.

[38] Grant, W. B., Holick, M. F., Benefits and requirements of vitamin D for optimal health: a review. Altern. Med. Rev. 2005, 10, 94-111.

[39] Heaney, R. P., The vitamin D requirement in health and disease. J. Steroid Biochem. Mol. Biol. 2005, 97, 13-19.

[40] Vieth, R., Bischoff-Ferrari, H., Boucher, B. J., Dawson-Hughes, B. et al., The urgent need to recommend an intake of vitamin $\mathrm{D}$ that is effective. Am. J. Clin. Nutr. 2007, 85, 649-650.

[41] Holick, M. F., Vitamin D status: measurement, interpretation, and clinical application. Ann. Epidemiol. 2009, 19, 73-78.

[42] Carter, G. D., Carter, C. R., Gunter, E., Jones, J. et al., Measurement of Vitamin D metabolites: an international perspective on methodology and clinical interpretation. J. Steroid Biochem. Mol. Biol. 2004, 89-90, 467-471.

[43] Aloia, J. F., African Americans, 25-hydroxyvitamin D, and osteoporosis: a paradox. Am. J. Clin. Nutr. 2008, 88, 545S-550S.

[44] Maetani, M., Maskarinec, G., Franke, A. A., Cooney, R. V., Association of leptin, 25-hydroxyvitamin $D$, and parathyroid hormone in women. Nutr. Cancer 2009, 61, 225-231.

[45] Harrison, S. L., Nowak, M., Buettner, P. G., Kimlin, M. G. et al., Public health and clinical dilemmas resulting from imprecise vitamin D tests. J. Rural Trop. Public Health 2009, 8, 52-58.

[46] Haddad, J. G., Chyu, K. J., Competitive protein-binding radioassay for 25-hydroxycholecalciferol. J. Clin. Endocrinol. Metab. 1971, 33, 992-995.

[47] Hollis, B. W., Burton, J. H., Draper, H. H., A binding assay for 25-hydroxycalciferols and 24R,25-dihydroxycalciferols using bovine plasma globulin. Steroids 1977, 30, 285-293.

[48] Belsey, R. E., DeLuca, H. F., Potts, J. T., Jr., A rapid assay for 25-OH-vitamin D3 without preparative chromatography. J. Clin. Endocrinol. Metab. 1974, 38, 1046-1051.

[49] Dorantes, L. M., Arnaud, S. B., Arnaud, C. D., Kilgust, K. A., Importance of isolation of 25-hydroxyvitamin-D before assay. J. Lab. Clin. Med. 1978, 91, 791-796.

[50] Hollis, B. W., Napoli, J. L., Improved radioimmunoassay for vitamin-D and its use in assessing vitamin-D status. Clin. Chem. 1985, 31, 1815-1819.

[51] Hollis, B. W., Kamerud, J. Q., Selvaag, S. R., Lorenz, J. D. et al., Determination of vitamin $\mathrm{D}$ status by radio- immunoassay with an 125I-labeled tracer. Clin. Chem. 1993 $39,529-533$.

[52] Carter, G. D., Jones, J. C., Berry, J. L., The anomalous behaviour of exogenous 25-hydroxyvitamin $\mathrm{D}$ in competitive binding assays. J. Steroid Biochem. Mol. Biol. 2007, 103, 480-482.

[53] Hollis, B. W., Comparison of commercially available (125)I-based RIA methods for the determination of circulating 25-hydroxyvitamin D. Clin. Chem. 2000, 46, 1657-1661.

[54] Carter, G. D., 25-Hydroxyvitamin D assays: the quest for accuracy. Clin. Chem. 2009, 55, 1300-1302.

[55] Kimball, S. M., Vieth, R., A comparison of automated methods for the quantitation of serum 25-hydroxyvitamin $D$ and 1,25-dihydroxyvitamin D. Clin. Biochem. 2007, 40, $1305-1310$

[56] Ersfeld, D. L., Rao, D. S., Body, J. J., Sackrison, J. L., Jr. et al., Analytical and clinical validation of the $25 \mathrm{OH}$ vitamin D assay for the LIAISON automated analyzer. Clin. Biochem. 2004, 37, 867-874.

[57] Souberbielle, J. C., Fayol, V., Sault, C., Lawson-Body, E. et al., Assay-specific decision limits for two new automated parathyroid hormone and 25-hydroxyvitamin D assays. Clin. Chem. 2005, 51, 395-400.

[58] Binkley, N., Krueger, D., Lensmeyer, G., 25-Hydroxyvitamin D measurement, 2009: a review for clinicians. J. Clin. Densitom. 2009, 12, 417-427.

[59] Carter, G. D., Carter, R., Jones, J., Berry, J., How accurate are assays for 25-hydroxyvitamin D? Data from the international vitamin $D$ external quality assessment scheme. Clin. Chem. 2004, 50, 2195-2197.

[60] Terry, A. H., Sandrock, T., Meikle, A. W., Measurement of 25-hydroxyvitamin D by the Nichols ADVANTAGE, DiaSorin LIAISON, DiaSorin RIA, and liquid chromatography-tandem mass spectrometry. Clin. Chem. 2005, 51, 1565-1566.

[61] Glendenning, P., Taranto, M., Noble, J. M., Musk, A. A. et al., Current assays overestimate 25-hydroxyvitamin D-3 and underestimate 25-hydroxyvitamin D-2 compared with HPLC: need for assay-specific decision limits and metabolite-specific assays. Ann. Clin. Biochem. 2006, 43, 23-30.

[62] Leino, A., Turpeinen, U., Koskinen, P., Automated measurement of 25-OH vitamin D3 on the Roche Modular E170 analyzer. Clin. Chem. 2008, 54, 2059-2062.

[63] Eisman, J. A., Shepard, R. M., DeLuca, H. F., Determination of 25-hydroxyvitamin D2 and 25-hydroxyvitamin D3 in human plasma using high-pressure liquid chromatography. Anal. Biochem. 1977, 80, 298-305.

[64] Maunsell, Z., Wright, D. J., Rainbow, S. J., Routine isotopedilution liquid chromatography-tandem mass spectrometry assay for simultaneous measurement of the 25-hydroxy metabolites of vitamins D-2 and D-3. Clin. Chem. 2005, 51, 1683-1690.

[65] Lensmeyer, G. L., Wiebe, D. A., Binkley, N., Drezner, M. K., HPLC method for 25-hydroxyvitamin D measurement: comparison with contemporary assays. Clin. Chem. 2006, $52,1120-1126$ 
[66] Zerwekh, J. E., Blood biomarkers of vitamin D status. Am. J. Clin. Nutr. 2008, 87, 1087S-1091S.

[67] Hollis, B. W., Horst, R. L., The assessment of circulating 25(OH)D and 1,25(OH)2D: where we are and where we are going. J. Steroid Biochem. Mol. Biol. 2007, 103, 473-476.

[68] Carter, G. D., Jones, J. C., Use of a common standard improves the performance of liquid chromatographytandem mass spectrometry methods for serum 25-hydroxyvitamin-D. Ann. Clin. Biochem. 2009, 46, 79-81.

[69] Pollack, A., The New York Times, New York 2009, p. B1, January 8.

[70] Coldwell, R. D., Trafford, D. J., Varley, M. J., Makin, H. L. et al., The measurement of vitamins D2 and D3 and seven major metabolites in a single sample of human plasma using gas chromatography/mass spectrometry. Biomed. Environ. Mass Spectrom. 1988, 16, 81-85.

[71] Carter, G. D., Nolan, J., Trafford, D. J. H., Makin, H. L. J., in: Norman, A. W., Bouillon, R., Thomasset, M. (Eds.), Vitamin D: Chemistry, Biology and Clinical Applications of the Seroid Hormone, University of California, Riverside 1997, pp. 737-738.

[72] Hollis, B. W., Kamerud, J. O., Kurkowski, A., Beaulieu, J. et al., Quantification of circulating 1,25-dihydroxyvitamin D by radioimmunoassay with $125 \mathrm{I}$-labeled tracer. Clin. Chem. 1996, 42, 586-592.

[73] Brumbaugh, P. F., Haussler, D. H., Bressler, R., Haussler, M. R., Radioreceptor assay for 1 alpha,25-dihydroxyvitamin D3. Science 1974, 183, 1089-1091.

[74] Clemens, T. L., Hendy, G. N., Graham, R. F., Baggiolini, E. G. et al., Radioimmunoassay for 1,25-dihydroxycholecalciferol. Clin. Sci. Mol. Med. 1978, 54, 329-332.

[75] Binkley, N., Krueger, D., Cowgill, C. S., Plum, L. et al., Assay variation confounds the diagnosis of hypovitaminosis $\mathrm{D}$ : a call for standardization. J. Clin. Endocrinol. Metab. 2004, 89, 3152-3157.

[76] Vitamin D External Quality Assessment Scheme (DEQAS). 25 Hydroxyvitamin D October 2009 Distribution, 2009.

[77] Lips, P., Chapuy, M. C., Dawson-Hughes, B., Pols, H. A. P. et al., An international comparison of serum 25-hydroxyvitamin D measurements. Osteoporos. Int. 1999, 9, 394-397.

[78] Singh, R. J., Taylor, R. L., Reddy, G. S., Grebe, S. K., C-3 epimers can account for a significant proportion of total circulating 25-hydroxyvitamin D in infants, complicating accurate measurement and interpretation of vitamin D status. J. Clin. Endocrinol. Metab. 2006, 91, 3055-3061.

[79] Glendenning, P., Issues of standardization and assayspecific clinical decision limits for the measurement of 25hydroxyvitamin D. Am. J. Clin. Nutr. 2003, 77, 522-523.

[80] Glendenning, P., Fraser, W. D., 25-OH-vitamin D assays. J. Clin. Endocrinol. Metab. 2005, 90, 3129.

[81] Phinney, K. W., Development of a standard reference material for vitamin D in serum. Am. J. Clin. Nutr. 2008, 88, 511S-512S

[82] Roth, H. J., Schmidt-Gayk, H., Weber, H., Niederau, C., Accuracy and clinical implications of seven 25-hydroxyvitamin $\mathrm{D}$ methods compared with liquid chromatography- tandem mass spectrometry as a reference. Ann. Clin. Biochem. 2008, 45, 153-159.

[83] Cavalier, E., Rozet, E., Gadisseur, R., Carlisi, A. et al., Measurement uncertainty of $25-\mathrm{OH}$ vitamin D determination with different commercially available kits: impact on the clinical cut offs. Osteoporos. Int. 2009, DOI 10.1007/ s00198-009-1052-5.

[84] McNally, J. D., Matheson, L. A., Sankaran, K., Rosenberg, A. M., Capillary blood sampling as an alternative to venipuncture in the assessment of serum 25 hydroxyvitamin D levels. J. Steroid Biochem. Mol. Biol. 2008, 112, 164-168.

[85] Eyles, D., Anderson, C., Ko, P., Jones, A. et al., A sensitive LC/MS/MS assay of $250 \mathrm{H}$ vitamin D3 and $25 \mathrm{OH}$ vitamin D2 in dried blood spots. Clin. Chim. Acta 2009, 403, 145-151.

[86] Lucas, R. M., Ponsonby, A. L., Pasco, J. A., Morley, R., Future health implications of prenatal and early-life vitamin D status. Nutr. Rev. 2008, 66, 710-720.

[87] Fairney, A., Saphier, P. W., Studies on the measurement of 25-hydroxy vitamin D in human saliva. Br. J. Nutr. 1987, 57, 13-25.

[88] Higashi, T., Shibayama, Y., Fuji, M., Shimada, K., Liquid chromatography-tandem mass spectrometric method for the determination of salivary 25-hydroxyvitamin D3: a noninvasive tool for the assessment of vitamin $D$ status. Anal. Bioanal. Chem. 2008, 391, 229-238.

[89] Hunter, D., De Lange, M., Snieder, H., MacGregor, A. J. et al., Genetic contribution to bone metabolism, calcium excretion, and vitamin $D$ and parathyroid hormone regulation. J. Bone Miner. Res. 2001, 16, 371-378.

[90] Orton, S. M., Morris, A. P., Herrera, B. M., Ramagopalan, S. V. et al., Evidence for genetic regulation of vitamin $D$ status in twins with multiple sclerosis. Am. J. Clin. Nutr. 2008, 88, 441-447.

[91] Torkildsen, O., Knappskog, P. M., Nyland, H. I., Myhr, K. M., Vitamin D-dependent rickets as a possible risk factor for multiple sclerosis. Arch. Neurol. 2008, 65, 809-811.

[92] Australia and New Zealand Multiple Sclerosis Genetics Consortium (ANZgene), Genome-wide association study identifies new multiple sclerosis susceptibility loci on chromosomes 12 and 20. Nat. Genet. 2009, 41, 824-828.

[93] Bailey, R., Cooper, J. D., Zeitels, L., Smyth, D. J. et al., Association of the vitamin D metabolism gene CYP27B1 with type 1 diabetes. Diabetes 2007, 56, 2616-2621.

[94] Daiger, S. P., Schanfield, M. S., Cavalli-Sforza, L. L., Groupspecific component $(\mathrm{Gc})$ proteins bind vitamin $\mathrm{D}$ and 25hydroxyvitamin D. Proc. Natl. Acad. Sci. USA 1975, 72, 2076-2080.

[95] Lauridsen, A. L., Vestergaard, P., Hermann, A. P., Brot, C. et al., Plasma concentrations of 25-hydroxy-vitamin $D$ and 1,25-dihydroxy-vitamin $D$ are related to the phenotype of $G c$ (vitamin D-binding protein): a cross-sectional study on 595early postmenopausal women. Calcif. Tissue Int. 2005, 77, 15-22.

[96] Kawakami, M., Blum, C. B., Ramakrishnan, R., Dell, R. B. et al., Turnover of the plasma-binding protein for vitamin-D and its metabolites in normal human-subjects. J. Clin. Endocrinol. Metab. 1981, 53, 1110-1116. 